\title{
P 167 PALLIATIVE EDUCATION FOR UNDERGRADUATE MEDICAL STUDENTS BASED ON THE NATIONAL SURVEY IN JAPAN
}

Kaichiro Tamba. Jichi Medical University, Shimotsuke, Japan

10.1136/bmjspcare-2014-000654.208

Background Palliative care education for undergraduate medical students has not been well established in Japan. A foundation supported our university to have a department of palliative care medicine for undergraduate palliative education for three years. Fortunately, a nationwide consensus syllabus of palliative medicine for undergraduate medical education had been developed.

Objectives To reflect the development of curriculum of palliative care for undergraduate.

Materials \& Methods Materials; (1) source of the syllabus, (2) source of teaching materials, (3) teaching staffs and supporters. Methods; evaluation by (1) development of the curriculum, (2) analysis of the budget, (3) analysis of the access of our website with Google analysis ${ }^{\circledR}$.

Results (1) Development of the curriculum; Number of the annual classes of palliative care increased from 13, 18, 22, respectively. (2) Analysis of the budget; $66.4 \%$ of annual expenditure was personnel expenses, $10.0 \%$ for administrative expenses, $6.0 \%$ for supplies expenses, $4.1 \%$ for travel expenses, $3.9 \%$ for appliances, 9.6\% for others. (3) Effect of disclosure of educational resources; the daily access to our website was significantly concentrated just before the national medical practitioners qualifying examination in Japan compared with that after the exam $(\mathrm{p}<0.0001)$.

Conclusions Experienced palliative staffs, total support by the university, moderate financial resource and developed syllabus enabled systematized palliative education for undergraduate medical students. It might propagate related to the national medical practitioners qualifying examination. 